\title{
Catalytic conversion of biomass-derived levulinic acid into $\gamma$-valerolactone using iridium nanoparticles supported on carbon nanotubes
}

\author{
DU Xianlong a,b, LIU Yongmei a , WANG Jianqiang b , CAO Yong a,*, FAN Kangnian a \\ a Department of Chemistry and Shanghai Key Laboratory of Molecular Catalysis and Innovative Materials, Fudan University, Shanghai 200433, China \\ bShanghai Institute of Applied Physics, Chinese Academy of Sciences, Shanghai 201800, China
}

\section{A R T I C L E I N F O}

Article history:

Received 17 November 2012

Accepted 21 December 2012

Published 20 May 2013

\section{Keywords:}

Biomass

Levilinic acid

$\gamma$-valerolactone

Hydrogenation

Iridium

Carbon nanotube

\begin{abstract}
A B S T R A C T
A new method has been developed for the catalytic conversion of biomass-derived levulinic acid (LA) into $\gamma$-valerolactone (GVL) with molecular hydrogen $\left(\mathrm{H}_{2}\right)$ using a series of heterogeneous noble metal catalysts. Excellent yields of the GVL were obtained under mild reaction conditions of $50^{\circ} \mathrm{C}$ and $2 \mathrm{MPa}$ of $\mathrm{H}_{2}$ using iridium nanoparticles supported on carbon nanotubes (Ir/CNT). It is noteworthy that the reaction proceeded smoothly in the presence of formic acid (FA, co-produced with LA in equimolar amounts during the acid-mediated hydrolysis of lignocellulosic biomass). Furthermore, the FA remained intact, highlighting the practical advantages of this process for the convenient and cost-effective processing of a biomass-derived LA/FA solution. The method is effective for the simultaneous production of GVL and FA from a wide variety of renewable biomass resources.
\end{abstract}

(C) 2013, Dalian Institute of Chemical Physics, Chinese Academy of Sciences. Published by Elsevier B.V. All rights reserved.

\section{Introduction}

Research into the effective utilization of renewable resources, such as biomass, has recently attracted considerable levels of attention because of the potential for these resources to be used as alternatives to petroleum for the production of chemicals and liquid fuels [1-5]. One strategy of particular interest involves the initial partial removal of oxygen from biomass to produce reactive intermediates, denoted as platform molecules, followed by the conversion of these molecules into the desired products [6,7]. $\gamma$-Valerolactone (GVL) has been suggested as a promising candidate molecule for this type of application because it possesses a variety of interesting properties that make it suitable for use as a new platform molecule in next-generation biorefineries [8]. GVL has many potential aplications, including its use as a solvent [9], food additive [10], and biofuel, where it could be used as a substitute for ethanol in gasoline-ethanol blends [11]. The hydrogenation of GVL provides access to methyltetrahydrofuran (MTHF), which is a potential fuel additive [1]. The selective formation of GVL from renewable resources therefore represents a highly desirable process and a promising move towards enhancing the sustainability of the chemical industry.

Extensive research efforts are currently being focused on the production of GVL from levulinic acid (LA), which can itself be produced at potentially low cost from the acid hydrolysis of

\footnotetext{
* Corresponding author. Tel: +86-21-55665287; Fax: +86-21-65643774; E-mail: yongcao@fudan.edu.cn This work was supported by the National Natural Science Foundation of China (21273044)), the Program for New Century Excellent Talents in University (NCET-09-0305), and Science \& Technology Commission of Shanghai Municipality (08DZ2270 500). 


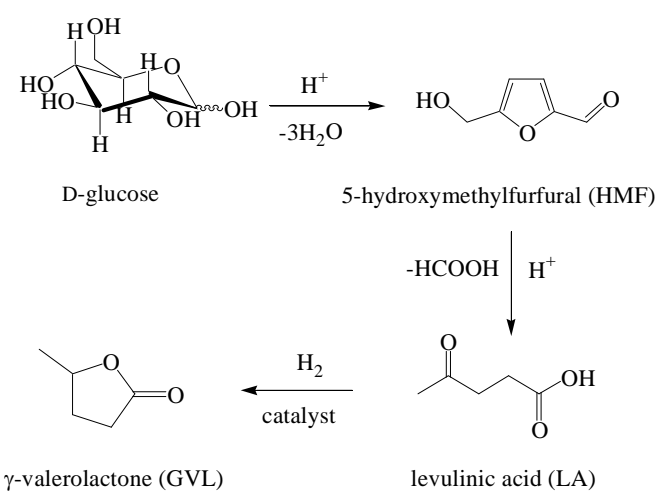

Scheme 1. Acid catalyzed hydrolysis of D-glucose to LA and subsequent hydrogenation of LA to GVL.

lignocellulosic biomass [12,13], as outlined in Scheme 1. Of the variety of different synthetic protocols that could be used for this transformation, the catalytic hydrogenations of LA using molecular hydrogen $\left(\mathrm{H}_{2}\right)$ [14-17] or formic acid [18,19] (FA), which is co-produced in equimolar amounts to LA during the acidic hydrolysis of the lignocellulosic biomass, have attracted considerable levels of attention in recent years.

The synthesis of GVL via the hydrogenation of LA using a heterogeneous catalyst was first reported using platinum oxide as the catalyst [14], where the formation of GVL occurred in moderate yields of up to $87 \%$ in a diethyl ether solvent following $44 \mathrm{~h}$ of reaction. When Raney Ni was evaluated as a catalyst for the transformation, a higher yield of GVL (94\%) was achieved at $220{ }^{\circ} \mathrm{C}$ under an initial hydrogen pressure of 48 atm (4.9 MPa) [15]. Recently, the hydrogenation of LA has been reported over a $\mathrm{Ru} / \mathrm{C}$ catalyst, with a GVL yield of up to $91 \%$ in a methanol solvent at $130{ }^{\circ} \mathrm{C}$ and under $12 \mathrm{~atm}(1.2 \mathrm{MPa})$ of $\mathrm{H}_{2}$ pressure [16]. In an attempt to reduce the temperature required of the transformation, Galletti et al. [17] reported the synthesis of GVL under milder conditions $\left(50-70{ }^{\circ} \mathrm{C}\right.$ and 0.5-3.0 MPa of $\mathrm{H}_{2}$ ) using a ruthenium supported catalyst in conjunction with an acidic co-catalyst, such as Amberlyst-70, niobium oxide or niobium phosphate. Efforts have also been made towards the use of FA as a straightforward and highly convenient hydrogen source [19,21,22]. Most recently, we have shown that a simple gold catalyst system composed of particularly small $\mathrm{Au}$ nanoparticles (NPs of ca. $1.8 \mathrm{~nm}$ ) deposited on $\mathrm{ZrO}_{2}\left(\mathrm{Au} / \mathrm{ZrO}_{2}\right.$-VS; VS = very small) can successfully convert the biomass-derived LA and FA into GVL without the requirement for an external $\mathrm{H}_{2}$ supply [23].

A number of homogeneous catalysts have also been reported for the hydrogenation of LA to GVL using molecular $\mathrm{H}_{2}$ or FA as the reducing agents. Ruthenium-based complexes with phosphine ligands were typically applied in these cases. For example, Osakada et al. [24] reported the use of $\mathrm{RuCl}_{2}\left(\mathrm{PPh}_{3}\right)_{3}$ as an effective catalyst for the hydrogenation of LA to GVL. The yield of GVL was reported to be as high as $99 \%$ when a $\mathrm{H}_{2}$ pressure of $11.8 \mathrm{~atm}(1.2 \mathrm{MPa})$ was used at $180{ }^{\circ} \mathrm{C}$ over a reaction period of $24 \mathrm{~h}$. Recently, Mehdi et al. [18] reported the use of $\mathrm{Ru}(\mathrm{acac})_{3}$ in combination with tri(3-sulfonatophenyl)phosphine (TPPTS) for the hydrogenation of LA to GVL in water at $140{ }^{\circ} \mathrm{C}$ and under $6.9 \mathrm{MPa}$ of $\mathrm{H}_{2}$ pressure. A GVL yield of $95 \%$ was achieved in this case following a reaction period of $12 \mathrm{~h}$. The transfer hydrogenation of LA with an excess of sodium formate (37 equiv.) catalyzed by $\left[\left(\eta^{6}-\mathrm{C}_{6} \mathrm{Me}_{6}\right) \mathrm{Ru}(\right.$ bpy $\left.)\left(\mathrm{H}_{2} \mathrm{O}\right)\right]\left[\mathrm{SO}_{4}\right]$ (bpy = 2,2'-bipyridine) was also examined. Both GVL and 1,4-pentanediol were obtained in $25 \%$ yield. Improved GVL yields (up to 95\%) were reported when a $\mathrm{RuCl}_{3} / \mathrm{PPh}_{3}$ complex was used in conjunction with copious amounts of base $\left(200^{\circ} \mathrm{C}, 6 \mathrm{~h}\right)[25]$.

Taken together, all of this research effectively highlights the great incentives that are available for the development of new environmentally benign catalytic systems for the efficient synthesis of GVL from biomass-derived LA under mild conditions. Carbon nanotubes (CNT) have been identified as promising support materials for many metal catalysts, especially for catalysts used in liquid-phase hydrogenation reactions, because of their fascinating physical and chemical characteristics [26,27]. Herein, we report that iridium nanoparticles (Ir NPs) supported on CNT effectively facilitated the convenient conversion of LA to GVL in the presence of $\mathrm{H}_{2}$ under mild aqueous conditions. Of particular significance is that the reaction even proceeded smoothly in the presence of FA, with the FA remaining intact and therefore offering practical advantages in terms of the potential for the direct processing of a biomass-derived LA/FA solution. The Ir-based metal catalysts, which had previously been established to be prominent for the chemoselective hydrogenation of a range of $\alpha, \beta$-unsaturated carbonyl compounds $[28,29]$, have been shown to be particularly useful for the hydrogenation of LA to produce GVL in an aqueous environment at temperatures as low as $50{ }^{\circ} \mathrm{C}$.

\section{Experimental}

\subsection{Catalyst preparation}

The multi-walled CNTs were typically pre-treated in concentrated $\mathrm{HNO}_{3}(68 \mathrm{wt} \%)$ at $120{ }^{\circ} \mathrm{C}$ under refluxing conditions to remove the remaining $\mathrm{Ni}$ catalyst and the amorphous carbon. Inductively coupled plasma (ICP) analysis showed that no Ni remained on the CNT following the treatment with $\mathrm{HNO}_{3}$. Activated carbon (C) was also pre-treated with concentrated $\mathrm{HNO}_{3}$ at $120{ }^{\circ} \mathrm{C}$ under refluxing conditions prior to its use. The deposition of Ir onto a variety of different supports (Ir loading, $4.5 \mathrm{wt} \%$ ) was achieved via a classical impregnation method with an aqueous solution of $\mathrm{H}_{2} \mathrm{IrCl}_{6}$ (Sigma-Aldrich), followed by a period of drying at $100^{\circ} \mathrm{C}$. The resulting catalysts were then subjected to $\mathrm{H}_{2} / \mathrm{Ar}(5 \mathrm{vol} \%)$ reduction at $300{ }^{\circ} \mathrm{C}$ for $2 \mathrm{~h}$. Other noble metal catalysts (Ir loading, $4.5 \mathrm{wt} \%$ ) were prepared using a similar impregnation method, except for $\mathrm{Ir} / \mathrm{MgO}$ which was reduced at $450^{\circ} \mathrm{C}$ for $2 \mathrm{~h}$ with $\mathrm{H}_{2} / \mathrm{Ar}$ (5 vol\%).

\subsection{Catalyst characterization}

The metal loadings of the catalysts were measured by inductively coupled plasma atomic emission spectroscopy (ICP-AES) using a Thermo Electron IRIS Intrepid II XSP spectrometer (Hitachi 4010). Powder X-ray diffraction (XRD) analyses of the catalysts were conducted on a Bruker D8 Advance 
$\mathrm{X}$-ray diffractometer (Bruker, Germany) using nickel filtered $\mathrm{Cu}$ $K_{\alpha}$ radiation $(\lambda=0.15418 \mathrm{~nm})$. A tube voltage of $40 \mathrm{kV}$ was used with a current of $40 \mathrm{~mA}$. X-ray photoelectron spectroscopy (XPS) analyses were performed using a Perkin Elmer PHI 5000C system equipped with a hemispherical electron energy analyzer. The $\mathrm{Mg} K_{\alpha}(h v=1253.6 \mathrm{eV})$ was operated at $15 \mathrm{kV}$ and $20 \mathrm{~mA}$. The energy scale was internally calibrated by setting the $\mathrm{C} 1 s$ peak at $284.6 \mathrm{eV}$. Transmission electron microscopy (TEM) images of the supported catalysts were taken with a JEOL 2011 electron microscope operating at $200 \mathrm{kV}$. Prior to being transferred into the TEM chamber, the samples dispersed with ethanol were deposited onto a carbon-coated copper grid and then quickly transferred into the vacuum evaporator. The temperature-programmed desorption characterization process was conducted with using bespoke apparatus that had been constructed in-house. The sample $(100 \mathrm{mg})$ was pretreated at $200{ }^{\circ} \mathrm{C}$ for $2 \mathrm{~h}$ and then cooled to $25^{\circ} \mathrm{C}$ in flowing He. At this temperature, sufficient pulses of $\mathrm{H}_{2}$ were injected until the occurrence of adsorption saturation. The system was then purged with $\mathrm{He}(30 \mathrm{ml} / \mathrm{min})$ for about $2 \mathrm{~h}$. The temperature was then raised from 25 to $650{ }^{\circ} \mathrm{C}$ at a ramp rate of $10^{\circ} \mathrm{C} / \mathrm{min}$ to desorb the $\mathrm{H}_{2}$. The desorbed $\mathrm{H}_{2}$ was monitored using an OmniStar mass spectrometer (QMS-200) with an m/e signal of 2 .

\subsection{Catalytic activity measurements}

\subsubsection{General procedure for LA hydrogenation}

The catalytic conversion of LA was performed in a stainless-steel autoclave (Parr Instrument, $25 \mathrm{ml}$ ) under 2.0 MPa of $\mathrm{H}_{2}$ pressure at $50{ }^{\circ} \mathrm{C}$ for $1 \mathrm{~h}$. For each reaction, $4.0 \mathrm{mmol} \mathrm{LA}$ (Sigma-Aldrich), $38.4 \mathrm{mg}$ catalyst, $2.0 \mathrm{mmol}$ 2-methoxyethyl ether (internal standard) and $10 \mathrm{ml}$ solvent were charged into the reactor and stirred at $800 \mathrm{r} / \mathrm{min}$. Upon completion of the reaction, the liquid products were analyzed on a Shimadzu GC-17A gas chromatograph equipped with a capillary column HP-FFAP ( $30 \mathrm{~m} \times 0.25 \mathrm{~mm}$ ) and an FID detector. The identification of the products was performed by using a GC-MS spectrometer via comparison with the commercially procured pure products.

\subsubsection{Hydrogenation of $L A$ in the presence of $F A$}

The catalytic conversions of LA were typically performed with an equimolar amount of FA in a $25 \mathrm{ml}$ Hastelloy-C high pressure Parr reactor under $4.0 \mathrm{MPa}$ of $\mathrm{H}_{2}$ pressure at $50{ }^{\circ} \mathrm{C}$. For each reaction, $4.0 \mathrm{mmol}$ of LA, $4.0 \mathrm{mmol}$ of FA, an Ir/CNT catalyst ( $\operatorname{lr} 1 \mathrm{~mol} \%$ ), and $10 \mathrm{ml}$ of water were charged into the reactor and the resulting mixture stirred at $800 \mathrm{r} / \mathrm{min}$. Upon completion of the reaction, the liquid products were analyzed on a high performance liquid chromatography (HPLC) system (HP1100, Agilent) equipped with an refractive index detector (RID) and Platisil ODS $\mathrm{C}_{18}$ column. $\mathrm{H}_{2} \mathrm{SO}_{4}(0.5 \mathrm{mmol} / \mathrm{L})$ was then added to the mobile phase at flow rate of $1 \mathrm{ml} / \mathrm{min}$. The column and detector temperatures were set at $40^{\circ} \mathrm{C}$.

\subsubsection{Hydrogenation of biomass-derived LA/FA solution}

Carbohydrate (1.8 g), consisting of cellulose, starch, sucrose, glucose, or fructose, was loaded into a teflon-lined stainless steel autoclave $(20 \mathrm{ml})$ followed by $10 \mathrm{ml}$ of a $0.5 \mathrm{~mol} / \mathrm{L} \mathrm{solu}-$ tion $\mathrm{H}_{2} \mathrm{SO}_{4}$. The autoclave was then rapidly heated to $170{ }^{\circ} \mathrm{C}$ and stirred vigorously for $1 \mathrm{~h}$. Upon completion of the reaction, the $\mathrm{pH}$ of the mixture was adjusted to a $\mathrm{pH}$ of 2 via the addition of $\mathrm{CaO}$ and the mixture was subsequently filtered to remove any insoluble humins [23]. The $\mathrm{CaO}$ was added to remove any residual $\mathrm{H}_{2} \mathrm{SO}_{4}$ because the resulting $\mathrm{CaSO}_{4}$ product could be used in the cement industry or as a soil conditioner. The carbohydrates-derived LA was then transferred to a $25 \mathrm{ml}$ Hastelloy-C high pressure Parr reactor containing Ir/CNT and subjected to catalytic hydrogenation at $50{ }^{\circ} \mathrm{C}$. The concentrations of the liquid products were determined using a HPLC system (HP1100, Agilent) equipped with an RID detector and a Platisil ODS $\mathrm{C}_{18}$ column. $\mathrm{H}_{2} \mathrm{SO}_{4}(0.5 \mathrm{mmol} / \mathrm{L})$ was added to the mobile phase at flow rate of $1 \mathrm{ml} / \mathrm{min}$.

\section{Results and discussion}

\subsection{Catalyst characterization}

The multiwalled CNT support was synthesized according to procedures previously described in the literature via the catalytic decomposition of $\mathrm{CH}_{4}$ over a $\mathrm{MgO}$-supported $\mathrm{Ni}$ catalyst [30,31]. The resulting CNT was purified with boiling nitric acid $\left(\mathrm{HNO}_{3}\right)$, and subsequently rinsed with de-ionized water and ethanol before being dried under dry nitrogen. The supported iridium catalysts (Ir content $\sim 4.5 \mathrm{wt} \%$ ) were then prepared using a classical impregnation method followed by $\mathrm{H}_{2}$ reduction at $300{ }^{\circ} \mathrm{C}$ for $2 \mathrm{~h}$. The resulting Ir NPs were then deposited onto the CNT (denoted as Ir/CNT, see details in the experimental section). TEM analysis of the Ir/CNT catalyst reveals that the particles had an average diameter of about $1.9 \mathrm{~nm}$ (Fig. 1(a)). Figure 2 shows the XRD patterns of the Ir/CNT catalyst. The peak intensities and their $2 \theta$ angles have been identified as characteristic of graphite. No diffraction lines assignable to metallic iridium could be detected for the Ir/CNT catalysts in Fig. 2(a), owing to the fact that the iridium particles were too small. All these results suggested that the iridium NPs were highly dispersed on the CNT surfaces. To identify the oxidation state of the Ir species on the CNTs, an XPS experiment was performed for the sample following the $\mathrm{H}_{2}$ reduction. The Ir $4 f$ peaks in the XPS spectra (Fig. 2(b)) showed that besides the main binding energy values at 60.8 and $63.9 \mathrm{eV}$, which were assigned to the $4 f_{7 / 2}$ and $4 f_{5 / 2}$ peaks of metallic iridium, binding energy values were also observed at 62.5 and $65.6 \mathrm{eV}$ and were assigned to the $4 f_{7 / 2}$ and $4 f_{5 / 2}$ peaks of iridium dioxide, respectively [32]. The presence of $\mathrm{IrO}_{2}$ was attributed to the aerial oxidation of nano-iridium particles and the incomplete reduction of $\mathrm{IrO}_{2}$. $\mathrm{Ir}^{0}$ was the active species for the reaction because the catalyst was not active to catalyze the hydrogenation prior to the reduction.

\subsection{General procedure for LA hydrogenation}

The conversion of LA was initially studied in a variety of different media at $50{ }^{\circ} \mathrm{C}$ under $2.0 \mathrm{MPa}$ of $\mathrm{H}_{2}$ pressure in the presence of the Ir/CNT catalyst. As shown in Table 1, a high 

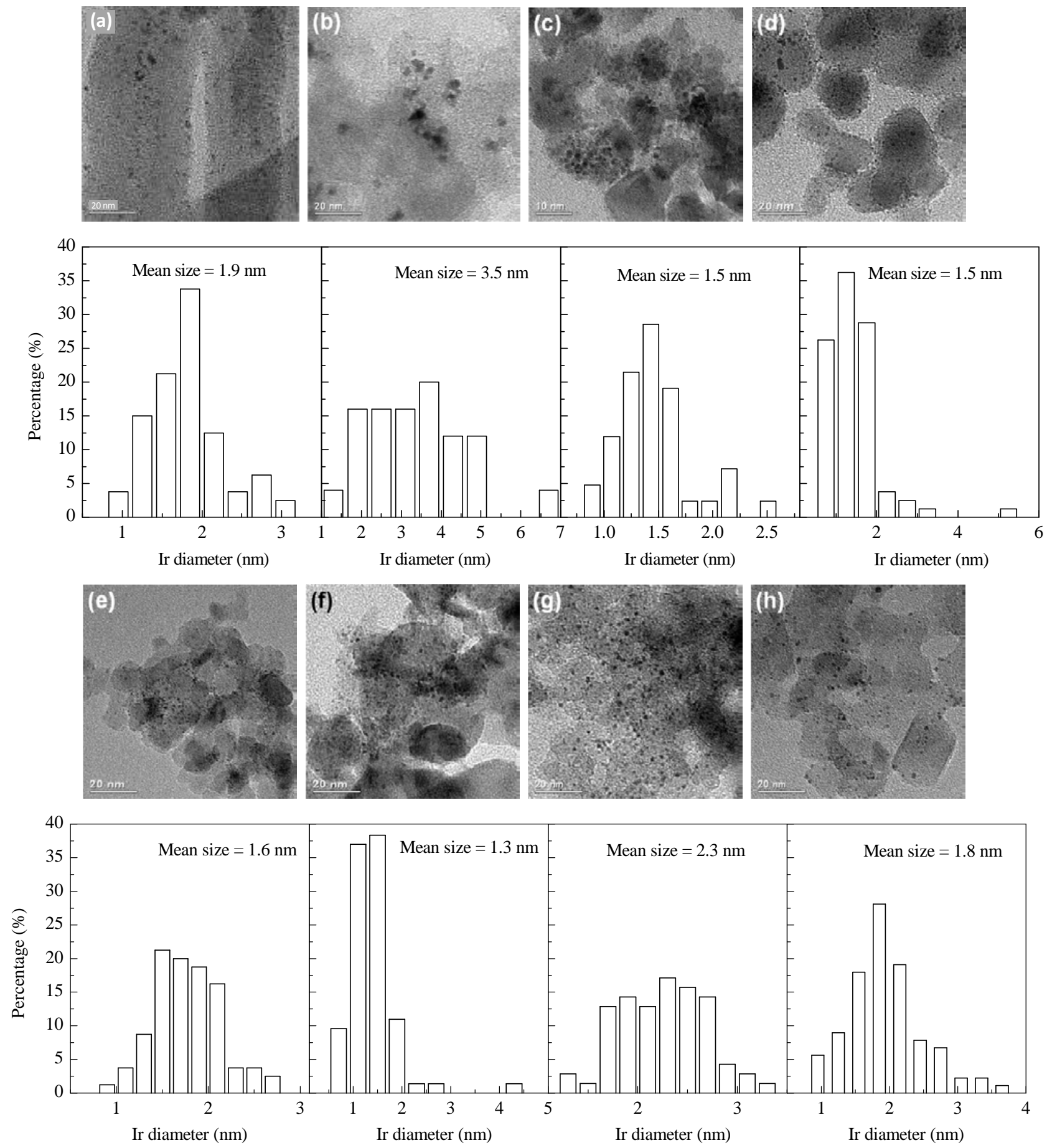

Fig. 1. Typical TEM micrographs and particle-size distributions for the supported iridium catalysts. (a) $\mathrm{Ir} / \mathrm{CNT}$; (b) $\mathrm{Ir} / \mathrm{C} ;(\mathrm{c}) \mathrm{Ir} / \mathrm{CeO}_{2} ;(d) \mathrm{Ir} / \mathrm{TiO}{ }_{2} ;(\mathrm{e})$ $\mathrm{Ir} / \mathrm{Al}_{2} \mathrm{O}_{3}$; (f) Ir/ZnO; (g) $\mathrm{Ir} / \mathrm{SiO}_{2}$; (h) Ir/MgO.

yield of GVL was obtained when $\mathrm{CHCl}_{3}$ was used as the reaction medium (Table 1, entry 1). In contrast, when toluene, methanol, acetone or dioxane were used as the solvent, the yield of GVL was lower (Table 1, entries 2-5). Surprisingly, water was found to be the best medium, providing an excellent yield of GVL after a reaction time of only $1 \mathrm{~h}$ (Table 1 , entry 6). This discovery represented a highly desirable development, not only because water is a safe, economical, and environmentally benign solvent [33], but also because LA is typically prepared via an acid-catalyzed hydrolysis process from an aqueous solution which provides the desired LA material in water [34]. The aqueous product solution of LA could therefore be telescoped directly into the current hydrogenation process to give GVL, representing an efficient sequence of transformations. Subsequent investigations revealed that the type of solid support used in the reduction process had a significant influence over the catalytic activity. Of the different supports tested, CNT was found to provide the best results. Activated carbon, $\mathrm{CeO}_{2}, \mathrm{TiO}_{2}$, 

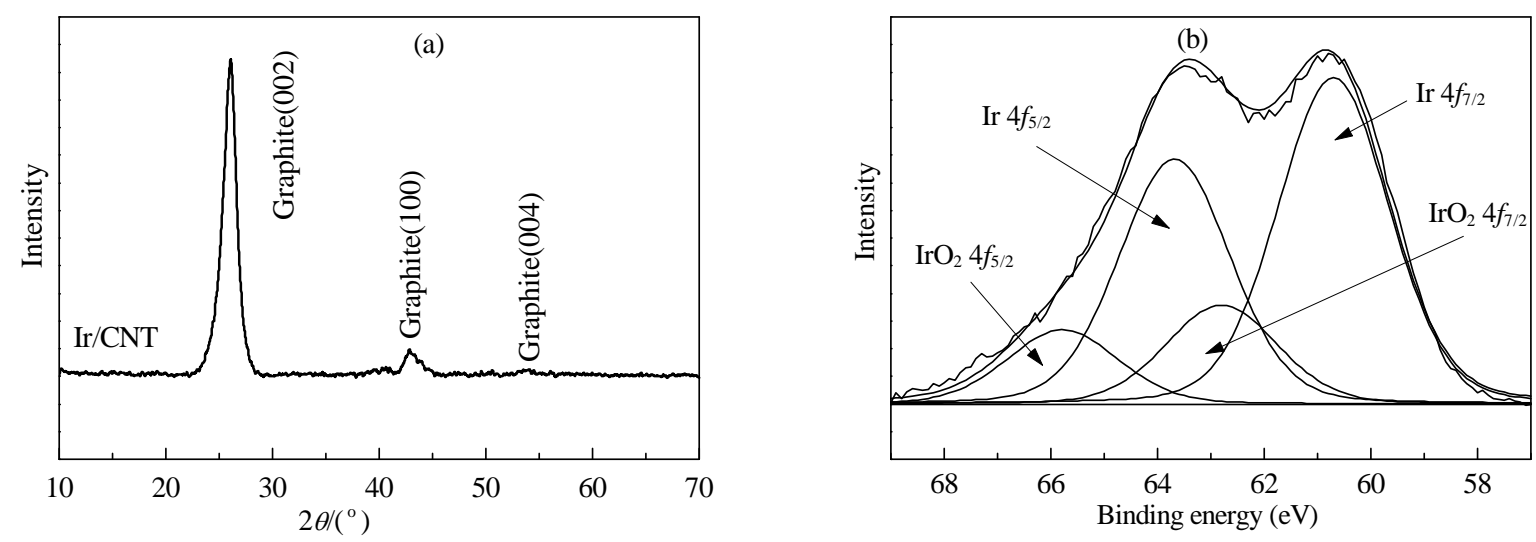

Fig. 2. XRD patterns (a) and XPS spectra (b) of the Ir/CNT catalyst reduced by $\mathrm{H}_{2}$ at $300^{\circ} \mathrm{C}$.

$\mathrm{Al}_{2} \mathrm{O}_{3}$ and $\mathrm{ZnO}$ were also effective (Table 1, entries 7-11), whereas $\mathrm{Ir} / \mathrm{SiO}_{2}$ and $\mathrm{Ir} / \mathrm{MgO}$ resulted in lower yields of the GVL (Table 1, entries 12 and 13). The use of other supported metals with catalytic potential, such as $\mathrm{Ru}, \mathrm{Pt}$, and $\mathrm{Pd}$, resulted in significantly lower yields of GVL from the conversion of LA conversion under similar reaction conditions (Table 1, entries 15-19). The fact that all of these supported iridium catalysts possessed metal particles with similar mean sizes (1.5-3.5 nm, see Fig. 1(b)-(h)) effectively highlighted the roles played by both the noble metal and the nature of the underlying support in the catalytic activity observed during the current LA hydrogenation process. Our results clearly show that the Ir/CNT catalyst possesses an optimal level of activity for the hydrogenation of LA in water under mild conditions. It is noteworthy that

Table 1

Catalytic properties of the supported Ir catalysts in different media.

\begin{tabular}{|c|c|c|c|c|c|}
\hline Entry & Solvent & Catalyst & $\begin{array}{c}\text { Conversion }^{\mathrm{a}} \\
(\%)\end{array}$ & $\begin{array}{c}\text { Selectivity }{ }^{\mathrm{b}} \\
(\%)\end{array}$ & $\begin{array}{c}\text { Yield } \\
(\%)\end{array}$ \\
\hline 1 & $\mathrm{CHCl}_{3}$ & Ir/CNT & 93 & 98 & 91 \\
\hline 2 & Toluene & Ir/CNT & 68 & 97 & 66 \\
\hline $3^{c}$ & Methanol & Ir/CNT & 20 & 90 & 18 \\
\hline 4 & Acetone & Ir/CNT & 7 & 99 & 7 \\
\hline 5 & Dioxane & $\mathrm{Ir} / \mathrm{CNT}$ & 2 & 100 & 2 \\
\hline 6 & Water & Ir/CNT & 100 & 99 & 99 \\
\hline $7^{d}$ & Water & $\mathrm{Ir} / \mathrm{C}$ & 78 & 98 & 76 \\
\hline 8 & Water & $\mathrm{Ir} / \mathrm{CeO}_{2}$ & 65 & 99 & 65 \\
\hline 9 & Water & $\mathrm{Ir} / \mathrm{TiO}_{2}$ & 55 & 99 & 55 \\
\hline 10 & Water & $\mathrm{Ir} / \mathrm{Al}_{2} \mathrm{O}_{3}$ & 52 & 98 & 51 \\
\hline 11 & Water & $\mathrm{Ir} / \mathrm{ZnO}$ & 51 & 99 & 51 \\
\hline 12 & Water & $\mathrm{Ir} / \mathrm{SiO}_{2}$ & 38 & 97 & 37 \\
\hline 13 & Water & Ir/MgO & 20 & 99 & 20 \\
\hline $14^{\mathrm{e}}$ & Water & $\mathrm{Ir} / \mathrm{CNT}$ & 96 & 97 & 95.1 \\
\hline 15 & Water & $\mathrm{Ru} / \mathrm{CNT}$ & 65 & 100 & 65.0 \\
\hline $16^{\mathrm{f}}$ & Water & $\mathrm{Ru} / \mathrm{Al}_{2} \mathrm{O}_{3}$ & 22 & 98 & 21.5 \\
\hline 17 & Water & $\mathrm{Pt} / \mathrm{CNT}$ & 53 & 97 & 51.4 \\
\hline 18 & Water & $\mathrm{Pd} / \mathrm{CNT}$ & 19 & 97 & 18.4 \\
\hline $19 \mathrm{~g}$ & Water & $\mathrm{Pd} / \mathrm{C}$ & 7 & 100 & 7.0 \\
\hline
\end{tabular}

Reaction conditions: catalyst (Ir loading, $4.5 \mathrm{wt} \%$ ), $4.0 \mathrm{mmol} \mathrm{LA,} \mathrm{Ir}$ ( $0.23 \mathrm{~mol} \%), 10 \mathrm{ml}$ solvent, $50^{\circ} \mathrm{C}, p\left(\mathrm{H}_{2}\right)=2.0 \mathrm{MPa}, 1 \mathrm{~h}$.

aConversion and selectivity were determined by GC and GC-MS with bis(2-methoxyethyl) ether as the internal standard. bUnless otherwise stated, hydroxyvaleric acid was the only side-product. cMethyl levulinate was identified as an additional side-product. ${ }^{\mathrm{d}} \mathrm{C}$ stands for activated carbon. eAfter four repeated uses. ${ }^{\mathrm{f}} 5 \mathrm{wt} \% \mathrm{Ru} / \mathrm{Al}_{2} \mathrm{O}_{3}$ (stock \# 11749), 5 wt \% Pd/C (stock \# 38300) provided by Alfa Aesar. the reaction could proceed efficiently even under solvent-free conditions. As shown in Scheme 2, an almost quantitative GVL yield was achieved for a $100 \mathrm{mmol}$ scale transformation of neat LA at $50{ }^{\circ} \mathrm{C}$. Of particular practical significance was the observation that the reaction even proceeded smoothly at ambient pressure, although a longer reaction time was required, which permitted the use of standard glass reactor systems (see Fig. 3).

Iridium catalysts have been used as highly active catalysts in a variety of hydrogen-involving reactions, and the catalytic activity of Ir is well-known to be critically dependent on the nature of the support [3-37]. To clarify the origin of the enhanced activity of the catalyst towards LA conversion when CNT was used as a support, $\mathrm{H}_{2}$ temperature-programmed desorption $\left(\mathrm{H}_{2}\right.$-TPD) measurements were conducted for the Ir NPs deposited on different supports. These measurements revealed that a significantly greater amount of $\mathrm{H}_{2}$ was desorbed from the Ir/CNT relative to the other catalysts (Fig. 4), implying that the high adsorption capacity of $\mathrm{H}_{2}$ associated with the Ir/CNT catalyst was responsible for its superior performance in the transformation of LA to GVL [38-42]. Furthermore, larger amounts of $\mathrm{H}_{2}$ were adsorbed over the catalysts on the CNT, C, and $\mathrm{TiO}_{2}$ supports, which highlighted the excellent correlation between this observation and their catalytic activity towards LA hydrogenation.

To better understand the GVL selectivity under different reaction conditions, the reaction pathway was considered. As shown in Scheme 3, there are two possible routes available for the production of GVL production, including (1) the hydrogenation of LA to hydroxyvaleric acid (HA) followed by dehydration to GVL (route a); or (2) the dehydration of LA to angelica lactone (AL) followed by hydrogenation to GVL (route b). It is known in the literature that LA dehydrates at moderate temperatures $\left(300-450{ }^{\circ} \mathrm{C}\right)$ in the presence of strong mineral or solid acids to give the corresponding cyclic product, AL (Scheme 3) $[43,44]$. Considering our mild reaction conditions $\left(<100^{\circ} \mathrm{C}\right)$ and the presence of HA (detected by GC-MS) as well as the absence of $\mathrm{AL}$, route a was envisaged to be the most likely pathway for the production of GVL from LA. The selectivity to GVL was found to be less than $100 \%$ (ca. 96\%) under very mild reaction conditions $\left(<50{ }^{\circ} \mathrm{C},<2 \mathrm{MPa}\right.$ of $\left.\mathrm{H}_{2}\right)$ because of the formation of the HA intermediate. Although the HA in- 


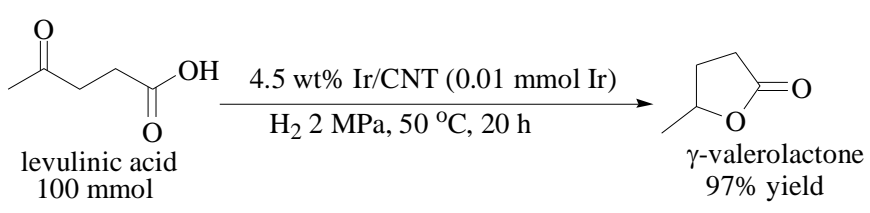

Scheme 2. Preparation of GVL from LA under solvent-free conditions.

termediate was found to be particularly unstable, its intra-molecular lactonization to GVL occurred with considerable ease [19]. Increases in the reaction temperature and $\mathrm{H}_{2}$ pressure allowed any HA formed to be readily dehydrated to form GVL and led to a higher level of GVL selectivity (Figs. 5 and 6). These results are consistent with the mechanism of GVL formation recently reported in the literature [17].

The reuse of the Ir/CNT catalyst was also studied. After each run, the catalyst was separated from the reaction mixture by filtration, thoroughly washed with water, and then reused as the catalyst for the next run under the same conditions. As shown in Table 1, the GVL yields remained high at 95\% for the first four successive cycles (Table 1 , entry 12), reflecting the high level of stability and reusability of the catalyst. The TEM and XPS results (Figs. 1 and 2) revealed no discernible changes in the mean diameters of the Ir NPs or in the metallic state of the Ir, respectively, following four successive runs. Further-

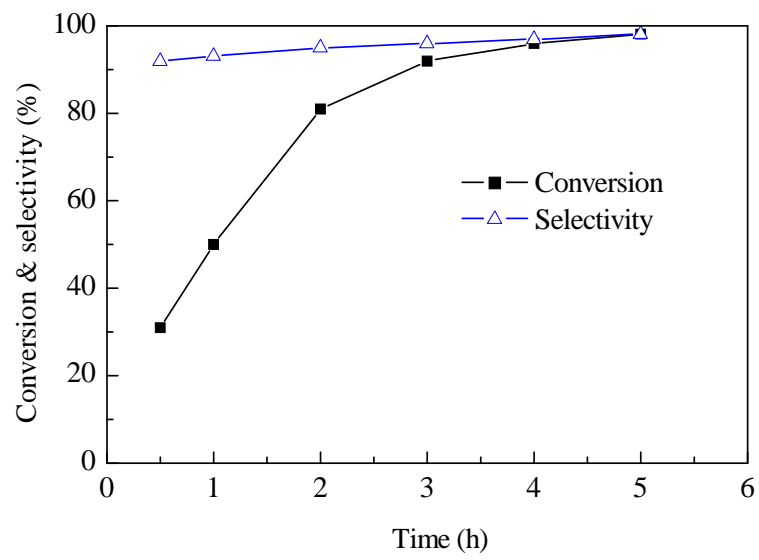

Fig. 3. Effect of reaction time on the catalytic performances of the 4.5 wt $\%$ Ir/CNT catalyst for the reduction of LA. Reaction conditions: 4.0 mmol LA, $0.23 \mathrm{~mol} \%$ Ir, water $10 \mathrm{ml} ; p\left(\mathrm{H}_{2}\right)=1 \times 10^{5} \mathrm{~Pa}, 50^{\circ} \mathrm{C}$. Note that the intermediate hydroxyvaleric acid was easily dehydration to GVL, affording a higher level of selectivity with extended reaction time. more, it was confirmed by ICP analysis that the Ir content of the used Ir/CNT catalyst was the same as that of the fresh catalyst and that no Ir was contained in the filtrate.

\subsection{Hydrogenation of LA in the presence of FA}

FA has recently attracted considerable interest from research focused on areas of green and sustainable chemistry because of its potential as a safe and convenient $\mathrm{H}_{2}$ carrier [45-47]. FA is currently produced industrially by the hydration of carbon monoxide as well as the hydrogenation of carbon dioxide [48]. Given the fact that FA is produced in equimolar amounts to LA during the hydrolysis of lignocellulosic biomass, we also studied the effect of FA on the catalytic conversion of LA (Table 2). The deliberate addition of an equimolar amount of FA to the hydrogenation system led to significant retardation of the LA hydrogenation process (Table 2, entry 1). Under the

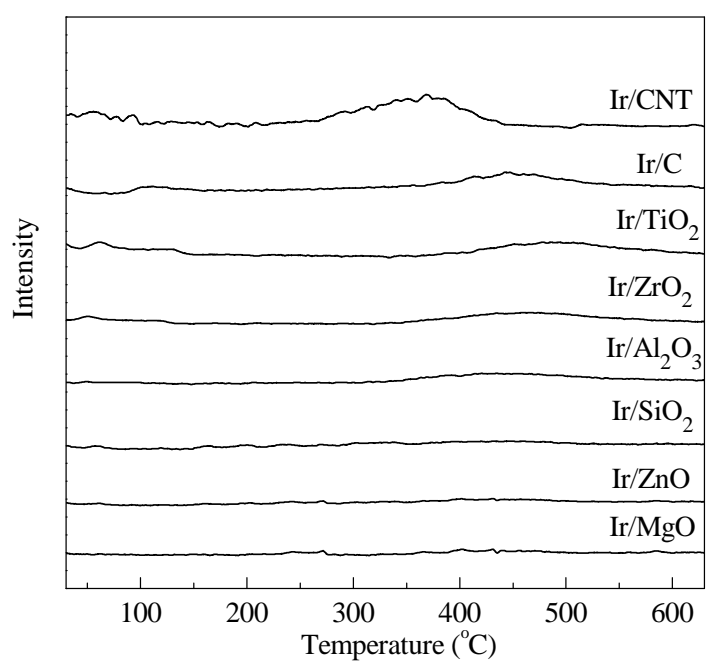

Fig. 4. $\mathrm{H}_{2}$-TPD profiles for the Ir catalysts supported on different supports.

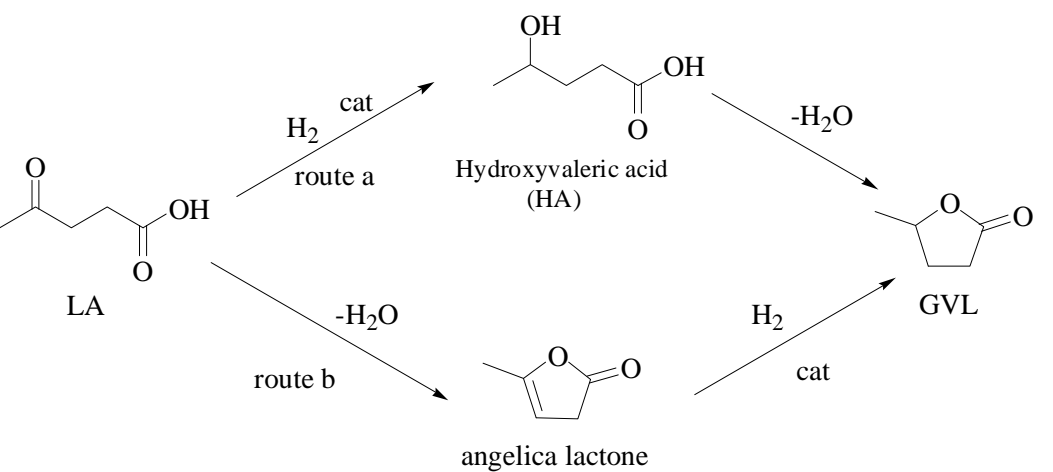

(AL)

Scheme 3. Mechanisms for LA hydrogenation. 




Fig. 5. Effect of reaction temperature on the catalytic performances of the $4.5 \mathrm{wt} \%$ Ir/CNT catalyst towards the reduction of LA. Reaction conditions: $4.0 \mathrm{mmol} \mathrm{LA}, 0.23 \mathrm{~mol} \% \mathrm{Ir}, 10 \mathrm{ml}$ water, $p\left(\mathrm{H}_{2}\right)=2.0 \mathrm{MPa}, 1$ h. Note that hydroxyvaleric acid was the only side-product.

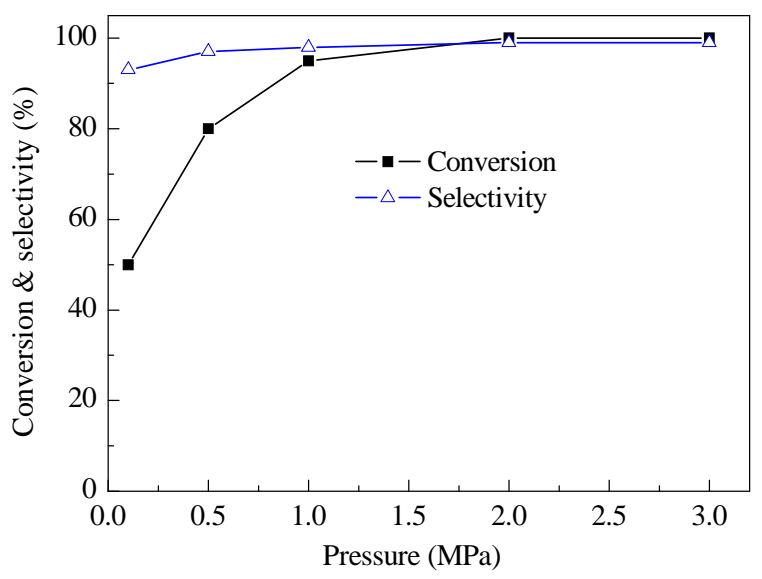

Fig. 6. Effect of $\mathrm{H}_{2}$ pressure on the catalytic performance of the $4.5 \mathrm{wt} \%$ Ir/CNT catalyst towards the reduction of LA. Reaction conditions: 4.0 mmol LA, $0.23 \mathrm{~mol} \% \mathrm{Ir}, 10 \mathrm{ml}$ water, $50{ }^{\circ} \mathrm{C}, 1 \mathrm{~h}$. Note that hydroxyvaleric acid was the only side-product.

same conditions, an extension in the reaction time to $12 \mathrm{~h}$ led to an increase in the GVL yield up to $50 \%$ (Table 2, entry 3). In an attempt to improve the GVL yield, the reaction was carried out at higher temperatures. Unfortunately, however, the yield of GVL decreased from 50 to $31 \%$ when the reaction temperature was raised to $100^{\circ} \mathrm{C}$ (Table 2, entry 4). Furthermore, an even lower GVL yield was obtained at the elevated temperature of $150^{\circ} \mathrm{C}$ (Table 2 , entry 5). Considering the notoriously low tolerance of platinum-group metals (PGM) toward CO in LA hydrogenation processes [23], the deactivation of the Ir/CNT catalyst in the current research was attributed to $\mathrm{CO}$ produced during the decomposition of FA at high reaction temperature. A separate control experiment was conducted to confirm the adverse impact of $\mathrm{CO}$ on the reaction. The experiment revealed that deliberate addition of small amount of $\operatorname{CO}(\sim 1,000 \mathrm{ppm})$ to the direct hydrogenation system has a significant negative effect on the LA hydrogenation process. Such effect of CO on the hydrogenation of LA over Ir/CNT catalyst is similar to other Pt-group based catalyst [23]. In a separate series of reactions,
Table 2

Hydrogenation of LA over 4.5 wt\% Ir/CNT catalyst by $\mathrm{H}_{2}$ with an equimolar amount of FA.

\begin{tabular}{cccccc}
\hline Entry & $\operatorname{Ir}(\mu \mathrm{mol})$ & $T /{ }^{\circ} \mathrm{C}$ & $t / \mathrm{h}$ & $\begin{array}{c}\text { Conversion }^{\mathrm{a}} \\
(\%)\end{array}$ & $\begin{array}{c}\text { Selectivity }^{\mathrm{b}} \\
(\%)\end{array}$ \\
\hline 1 & 9.2 & 50 & 1 & 9 & 98 \\
2 & 9.2 & 50 & 6 & 32 & 99 \\
3 & 9.2 & 50 & 12 & 50 & 99 \\
4 & 9.2 & 100 & 12 & 31 & 99 \\
5 & 9.2 & 150 & 12 & 8 & 99 \\
6 & 40 & 50 & 12 & 80 & 99 \\
$7^{\mathrm{d}}$ & 40 & 50 & 12 & 96 & 99 \\
$8^{\mathrm{e}}$ & 40 & 50 & 12 & 0 & - \\
\hline
\end{tabular}

Reaction conditions: $4.0 \mathrm{mmol} \mathrm{LA}, 4.0 \mathrm{mmol} \mathrm{FA,} 10 \mathrm{ml}$ water, $p\left(\mathrm{H}_{2}\right)=$ 2.0 MPa. aConversion determined by HPLC. ${ }^{b}$ Hydroxyvaleric acid is the only side-product. $c 4.0 \mathrm{mmol} \mathrm{LA}, 4.0 \mathrm{mmol} \mathrm{FA}, 10 \mathrm{ml}$ water, $p\left(\mathrm{H}_{2}\right)=4.0$ $\mathrm{MPa}$. As monitored by HPLC, the concentration of FA remained constant during the reaction. ${ }^{e} 4.0 \mathrm{mmol} \mathrm{LA}, 4.0 \mathrm{mmol} \mathrm{FA}, 10 \mathrm{ml}$ water, $P\left(\mathrm{~N}_{2}\right)=$ $2.0 \mathrm{MPa}$.

the hydrogenation was conducted at lower temperatures but with elevated $\mathrm{H}_{2}$ pressures to improve the reaction kinetics. Pleasingly, the yield of GVL could be significantly improved by an increase in the amount of catalyst or $\mathrm{H}_{2}$ pressure (Table 2, entries 6 and 7). The highest GVL yield observed was 96\% with $1 \mathrm{~mol} \%$ Ir at $4 \mathrm{MPa}$ of $\mathrm{H}_{2}$ pressure in $12 \mathrm{~h}$ (Table 2, entry 7).

Importantly, the results revealed that the FA concentration remained constant (Table 2, entry 7) following the hydrogenation of LA with the Ir/CNT catalysts at $50^{\circ} \mathrm{C}$ over a period of 12 h. This lack of change was attributed to the reaction conditions being too mild to allow for the decomposition of FA in this particular case. A separate control experiment involving the application of the standard conditions to an equimolar mixture of LA and FA under a $2.0 \mathrm{MPa}$ nitrogen $\left(\mathrm{N}_{2}\right)$ for $12 \mathrm{~h}$ confirmed that transfer hydrogenation of LA did not take place in the absence of $\mathrm{H}_{2}$ (Table 2, entry 8). The fact that any unproductive decomposition of FA could be largely controlled by the careful choice of conditions made it possible to extract the GVL and FA with high levels of efficiency from water using the appropriate extraction solvents [22]. Given that both FA and LA are organic acids and have similar properties, it can be very difficult to separate these two products. However, given that GVL is more hydrophobic than LA and FA and that there is a significant difference in the boiling points of GVL and FA [22], a convenient and cost-effective separation of FA from GVL could be realized based on these properties.

\subsection{Hydrogenation of biomass-derived LA/FA solution}

To demonstrate the utility of the Ir/CNT catalyst in the context of biomass-derived substrates, we investigated the hydrogenation of LA obtained from the hydrolysis of D-glucose. A mixture of LA and FA was obtained the hydrolysis of D-glucose in the presence of $\mathrm{H}_{2} \mathrm{SO}_{4}(0.5 \mathrm{~mol} / \mathrm{L})$. Following the partial neutralization of the material and the subsequent removal of the insoluble humins by filtration (see experiment section for details), the hydrolyzed solution was transferred to an autoclave containing Ir/CNT and subjected to an reaction under 4.0 $\mathrm{MPa}$ of $\mathrm{H}_{2}$ pressure at $50{ }^{\circ} \mathrm{C}$ for $12 \mathrm{~h}$. It is important to note 
Table 3

Dehydration of carbohydrates ${ }^{\mathrm{a}}$ and subsequent hydrogenation of carbohydrate-derived LA using Ir/CNT as a catalyst ${ }^{\mathrm{b}}$.

\begin{tabular}{lcccc}
\hline \multirow{2}{*}{ Entry } & \multirow{2}{*}{ Carbohydrate } & \multicolumn{3}{c}{ Yield (\%) } \\
\cline { 3 - 5 } & & $\mathrm{LA}^{\mathrm{c}}$ & $\mathrm{FA}^{\mathrm{c}}$ & $\mathrm{GVL}^{\mathrm{d}}$ \\
\hline 1 & Glucose & 54 & 58 & $52(96)$ \\
2 & Fructose & 61 & 67 & $60(98)$ \\
3 & Sucrose & 58 & 65 & $56(97)$ \\
4 & Starch & 52 & 60 & $50(96)$ \\
5 & Cellulose & 34 & 40 & $32(94)$ \\
\hline
\end{tabular}

a Reaction conditions: $1.8 \mathrm{~g}$ carbohydrate, $20 \mathrm{ml}$ water, $0.5 \mathrm{~mol} / \mathrm{L} \mathrm{H}_{2} \mathrm{SO}_{4}$ $180^{\circ} \mathrm{C}, p\left(\mathrm{~N}_{2}\right)=0.5 \mathrm{MPa}, 1 \mathrm{~h}$.

${ }^{b}$ Reaction conditions: as-prepared dehydration solution, $0.43 \mathrm{~g}$ catalyst (Ir loading, $4.5 \mathrm{wt} \%$ ), $50^{\circ} \mathrm{C}, p\left(\mathrm{H}_{2}\right)=4.0 \mathrm{MPa}$.

cYield for the initial carbohydrate hydrolysis.

d Overall yield for the two-stage conversion of the biomass-derived carbohydrate. The yield based on conversion of LA is given in parenthesis.

that, without isolation of the insoluble hydrolysis by-products, the subsequent LA hydrogenation is very slow under the as described reaction conditions, possibly due to a strong adsorption of humids to the iridium metal catalysts. Under these conditions, GVL was produced in $96 \%$ yield. The overall yield of GVL from glucose was approximately $52 \%$ (Table 3, entry 1 ). Further improvements to the GVL yield were achieved when D-fructose was used instead of D-glucose. The highest GVL yield was $60 \%$ following complete D-fructose conversion (Table 3 , entry 2). Dimeric sugar (sucrose), a polymer (starch), and cellulose were also tested under the optimized conditions determined for D-glucose. In all three cases, near-complete conversion of the biomass-derived LA into GVL was observed (Table 3 , entries 3-5), and the GVL was formed in 56\%, 50\%, and 32\% overall yields, respectively. To the best of our knowledge, these results represent an unprecedented example of the simultaneous production of GVL and FA from renewable biomass resources via a simple and convenient catalytic hydrogenation under mild reaction conditions.

\section{Conclusions}

We have developed an efficient process for the hydrogenation of LA based on the use of CNT-supported Ir nanoparticles as a new heterogeneous catalyst. The method is highly effective and applicable to the hydrogenation of LA using $\mathrm{H}_{2}$ even in the presence of FA under mild aqueous conditions, with the FA remaining unchanged. The method is effective for the simultaneous production of GVL and FA from a wide variety of renewable biomass resources. A convenient and cost-effective separation of FA from GVL can be realized because of the difference in the polarities and boiling points of GVL and LA.

\section{References}

[1] Kamm B, Grube P R, Kamm M. Biorefineries-Industrial Processes and Products: Status Quo and Future Directions. Vol. 1. Weinheim: Wiley-VCH, 2006

[2] Corma A, Iborra S, Velty A. Chem Rev, 2007, 107: 2411

[3] Liu Z, Feng G, Pan Ch Y, Li W, Chen P, Lou H, Zheng X M. Chin J
Catal (刘镇, 冯刚, 潘春燕, 李望, 陈平, 楼辉, 郑小明. 催化学报), 2012, 33: 1696

[4] Shuttleworth P, Budarin V, Gronnow M, Clark J H, Luque R. J Nat Gas Chem, 2012, 21: 270

[5] Luque R, Pineada A, Colmenares J C, Campelo J M, Romero A A, Serrano-Ruiz J C, Cabeza L F, Got-Gores J. J Nat Gas Chem, 2012, 21: 246

[6] Clause P, Vogel H. Chem Eng Technol, 2008, 31: 678

[7] Bozell J J, Petersen G R. Green Chem, 2010, 12: 539

[8] Bond J Q, Alonso D M, West R M, Dumesic J A. Langmuir, 2010, 26 : 16291

[9] Horváth I T. Green Chem, 2008, 10: 1024

[10] Dunlop A P, Madden J W. US Patent 2786852. 1957

[11] Horváth I T, Methdi H, Fábos V, Boda L, Mika L T. Green Chem, 2008, 10: 238

[12] Fitzpatrick S W. US Patent 5608105. 1997

[13] Bozell J J, Elliott D C, Wang Y, Neuenscwander G G, Fitzpatrick S W, Bilski R J, Jarnefeld J L. Resour Conserv Recycl, 2000, 28: 227

[14] Schuette H A, Thomas R W. J Am Chem Soc, 1930, 52: 3010

[15] Christian R V, Brown H D, Hixon R M. J Am Chem Soc, 1947, 69: 1961

[16] Yan Z P, Liu L, Liu S J. Energy Fuels, 2009, 23: 3853

[17] Galletti A M R, Antonetti C, Luise V D, Martinelli M. Green Chem, 2012, 14: 688

[18] Mehdi H, Fábos V, Tuba R, Bodor A, Mika L T, Horváth I T, Top Catal, 2008, 48: 49

[19] Heeres H, Handana R, Chunai D, Rasrendra C B, Girisuta B, Heeres H J. Green Chem, 2009, 11: 1247

[20] Bourne R A, Stevens J G, Ke J, Poliakoff M. Chem Commun, 2007: 4632

[21] Deng L, Zhao Y, Li J, Fu Y, Liao B, Guo Q X. ChemSusChem, 2010, 3: 1172

[22] Serrano-Ruiz J C, Braden D J, West R M, Dumesic J A. Appl Catal B, 2010, 100: 184

[23] Du X L, He L, Zhao S, Liu Y M, Cao Y, He H Y, Fan K N. Angew Chem, Int $E d, 2011,50: 7815$

[24] Osakada K, Ikariya T, Yoshikawa S. J Organomet Chem, 1982, 231: 79

[25] Deng L, Li J, Lai D M, Fu Y, Guo Q X. Angew Chem, Int Ed, 2009, 48: 6529

[26] Pan X L, Fan Z L, Chen W, Ding Y J, Luo H Y, Bao X H, Nat Mater, 2007, 6: 507

[27] Chen W, Fan Z L, Pan X L, Bao X H, J Am Chem Soc, 2008, 130: 9414

[28] Debruyn M, Coman S, Bota R, Parvulescu V I, De Vos D E, Jacobs P A. Angew Chem, Int Ed, 2003, 42: 5333

[29] Rojas H, Borda G, Martínez J J, Valencia J, Reyes P. J Mol Catal A, 2008, 286: 70

[30] Chen P, Zhang H B, Lin G D, Hong Q, Tsai K R. Carbon, 1997, 35: 1495

[31] Zhang Y, Zhang H B, Lin G D, Chen P, Yuan Y Z, Tsai K R. Appl Catal A, 1999, 187: 213

[32] Moulder J F, Stickle W F, Sobol P E, Bomben K D. Handbook of X-ray Photoelectroscope. Eden Prairie: Physical Electronics, Inc., 1995

[33] Kobayashi S, Manabe K. Acc Chem Res, 2002, 35: 209

[34] Girisuta B, Janssen L P B M, Heeres H J. Chem Eng Re Des, 2006, 84: 339

[35] López-De Jesús Y M, Vicente A, Lafaye G, Marécot P, Williams C T.J Phys Chem C, 2008, 112: 13837

[36] Silvennoinen R J, Jylhä O J T, Lindblad M, Österholm H, Krause A 0 I. Catal Lett, 2007, 114: 135

[37] Sugii T, Kamiya Y, Okuhara T. Appl Catal A, 2006, 312: 45 


\title{
Graphical Abstract
}

Chin. J. Catal., 2013, 34: 993-1001 doi: 10.1016/S1872-2067(11)60522-6

\section{Catalytic conversion of biomass-derived levulinic acid into $\gamma$-valerolactone using iridium nanoparticles supported on carbon nanotubes}

DU Xianlong, LIU Yongmei, WANG Jianqiang, CAO Yong*,

FAN Kangnian

Fudan University;

Shanghai Institute of Applied Physics, Chinese Academy of Sciences

Iridium nanoparticles supported on carbon nanotubes have been used as a highly efficient catalyst for the hydrogenation of biomass-derived levulinic acid to $\gamma$-valerolactone (GVL) in the presence of formic acid. The GVL was obtained in an excellent yield of $96 \%$ at an operating temperature of $50^{\circ} \mathrm{C}$.

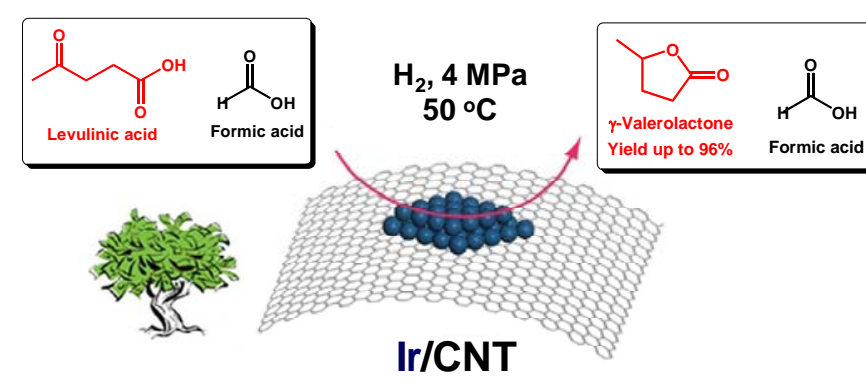

68: 73

[44] Kitano M, Tanimoto F, Okabashi M. Chem Econ Eng Rev, 1975, 7: 25

[45] Loges B, Boddien A, Junge H, Beller M. Angew Chem, Int Ed, 2008, 47: 3962

[46] Boddien A, Loges B, Junge H, Beller M. ChemSusChem, 2008, 1: 751

[47] Enthaler S. ChemSusChem, 2008, 1: 801

[48] Reutemann W, Kieczka H. Formic Acid in Ullmann's Encyclopedia of Industrial Chemistry. Weinheim: Wiley-VCH, 2005

[43] Timokhin B V, Baransky V A, Eliseeva G D. Russ Chem Rev, 1999,

\section{碳纳米管担载纳米 $I r$ 催化生物质基乙酰丙酸合成 $\gamma$-戊内酯}

\author{
杜贤龙 ${ }^{\mathrm{a}, \mathrm{b}}$ ，刘永梅 ${ }^{\mathrm{a}}$ ，王建强 ${ }^{\mathrm{b}}$ ，曹 勇 ${ }^{\mathrm{a}, *}$ ，范康年 ${ }^{\mathrm{a}}$
}

a复旦大学化学系, 上海市分子催化和功能材料重点实验室, 上海200433

b 中国科学院上海应用物理研究所, 上海201800

摘要: 以碳纳米管(CNTs)担载Ir纳米粒子为催化剂进行生物质基平台化合物乙酰丙酸(LA)选择加氢制备 $\gamma-$ 戈内酯(GVL)的研究, 并利用X射线衍射、X射线光电子能谱和透射电镜表征了使用前后的Ir/CNT催化剂, 探讨了影响LA催化加氢制GVL反应性能的因 素和该反应的可能路径. 结果表明, 与 $\mathrm{Ru}, \mathrm{Rh}$ 和Pd等传统铂族金属相比, Ir/CNT催化剂不但可在温和条件下 $\left(50^{\circ} \mathrm{C}, 2.0 \mathrm{MPa}, \mathrm{H}_{2}\right)$ 实现LA至GVL的完全转化, 且可对多类直接源于生物质水解的含等量LA/甲酸的 “真实” 体系实现GVL的高效选择合成. 关键词: 生物质; 乙酰丙酸; $\gamma$-戊内酯; 加氢; 铱; 碳纳米管

收稿日期: 2012-11-17. 接受日期: 2012-12-21. 出版日期: 2013-05-20.

*通讯联系人.电话: (021)55665287; 传真: (021)65643774; 电子信箱: yongcao@fudan.edu.cn

基金来源：国家自然科学基金(21273044); 新世纪优秀人才支持计划(NCET-09-0305); 上海市科委项目(08DZ2270500).

本文的英文电子版由Elsevier出版社在ScienceDirect上出版(http://www.sciencedirect.com/science/journal/18722067). 